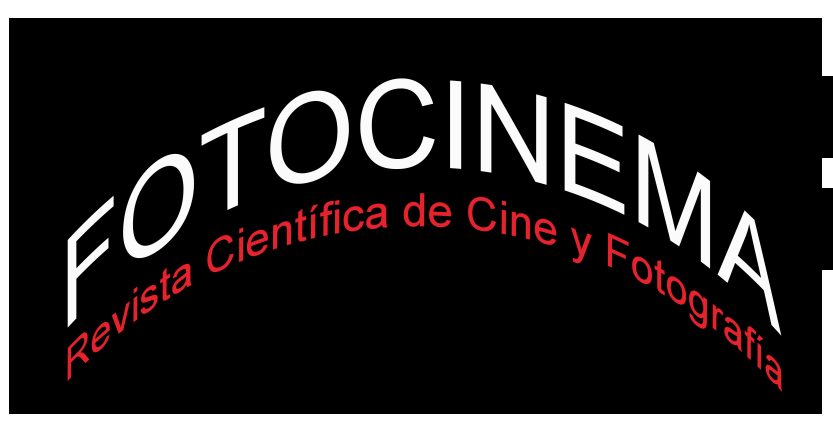

\title{
UN MODELO SIN MODELO. REPENSAR LA HISTORIA DE LA FOTOGRAFÍA EN ESPAÑ̃
}

\section{A MODEL-LESS MODEL. RE-THINKING THE HISTORY OF PHOTOGRAPHY IN SPAIN}

\author{
Carmelo Vega \\ Universidad de La Laguna, España \\ cvega@ull.edu.es
}

\section{Resumen:}

A comienzos de los años 80 aparecieron los primeros libros relacionados con la historia de la fotografía española. La falta de modelos y metodologías específicas, la ausencia de una historiografía nacional previa, la escasa información sobre la materia y la pluralidad de enfoques implicados provocaron la dispersión de objetivos y una insuficiente reflexión teórica sobre los métodos históricos aplicados. El dilema entre la historia general de la fotografía española $\mathrm{y}$ las historias locales de la fotografía en cada una de las regiones de España, ha marcado el desarrollo y los avances de esta disciplina en las últimas tres décadas, y plantea un interesante debate sobre la "distancia adecuada" que el historiador debe tener respecto al objeto de su investigación. La necesidad de renovar y actualizar la historia de la fotografía en España pasa por una reflexión sobre las metodologías empleadas hasta ahora y por profundizar en el conocimiento, el análisis y la definitiva recuperación del patrimonio fotográfico español.

\begin{abstract}
:
The first books on the history of photography in Spain were published in the early 80s. The lack of specific models and methodologies, the absence of a previous national historiography, the limited information on the subject and the plurality of approaches involved caused the dispersion of objectives and an insufficient theoretical reflection on the historical methods applied. The dilemma between a general history of Spanish photography and local histories of photography in each of the regions of Spain, has marked the development and progress of this discipline in the last three decades, and raises an interesting discussion about the "appropriate distance" that the historian must have regard on the object of their research. The need to renew and update the history of photography in Spain, goes through a reflection on the methodologies used so far and deepen the knowledge, analysis and definitive recuperation of Spanish photographic heritage.
\end{abstract}

\section{Palabras clave:}

Historia; fotografía; España; historia local; historia general; metodologías.

\section{Keywords:}

History; photography; Spain; local history; general history; methodologies. 


\section{Introducción}

Existe una historia de la historia de la fotografía en España. Aunque reciente, no es una historia breve, y participa de esa misma complejidad crítica que la historiografía contemporánea enmarca dentro de las tesis de los modelos

plurales y antinormativos: no hay una historia única de la fotografía sino historias de la fotografía que nos permiten ajustar una mirada polimórfica y abierta a la fotografía como fenómeno histórico.

Para muchos investigadores extranjeros, la historiografía española sobre fotografía presenta una serie de singularidades determinadas por el carácter específico y diferenciado de ciertas metodologías utilizadas. El reconocimiento de esa particularidad ha coincidido con el desarrollo de unos procesos de autorrevisión de los modos de hacer la historia de la fotografía. Más allá de la atención puntual y pasajera, conviene indagar en los motivos de este interés desde fuera de España por la fotografía española y por la historia de la fotografía en España: ¿por qué ahora ese deseo de profundizar en las peculiaridades de un modelo historiográfico español? La respuesta a esta pregunta no puede desligarse del papel que España ha jugado en el contexto de la historia de la fotografía europea o mundial, es decir, un papel secundario y periférico. Y es precisamente desde la aceptación de esa condición de periferia, donde nuestra historia de la fotografía podría presentar algunas prácticas alternativas interesantes frente a unos modelos históricos dominantes que han demostrado la imposibilidad de ofrecer soluciones normativas globales.

\section{Marco teórico: de una historia invisible a la hipermetropía de la historia}

Hemos dicho secundario y periférico pero convendría precisar un poco más. $\mathrm{Si}$ repasamos las historias generales de la fotografía más conocidas publicadas hasta los años 70, como las de Beaumont Newhall o Helmut Gernsheim, comprobaremos que la fotografía española o no existía o su 
aportación, salvo algunos casos excepcionales, era insignificante o tangencial. He aquí una paradoja inicial a la que tuvieron que enfrentarse los primeros historiadores de la fotografía en España: las referencias bibliográficas y los modelos historiográficos que se usaban en aquellos momentos eran historias generales de la fotografía en las que la fotografía española era invisible porque carecía de historia. Así pues, desde finales de la década de los 70, aquello sobre lo que un colectivo no demasiado numeroso de historiadores y de aficionados a la fotografía investigaba y comenzaba a difundir a través de libros y artículos, aquello sobre lo que se hablaba y discutía en reuniones, jornadas y congresos, aquello que se intentaba fundamentar como una nueva línea de investigación universitaria, todo aquello era una materia desconocida, indocumentada y oculta que había sido ignorada durante décadas no ya por los grandes historiadores de la fotografía mundial sino por los propios investigadores e historiadores españoles ${ }^{1}$.

Por supuesto, trabajar en un territorio inexplorado del conocimiento y de la creación humana resulta siempre muy atractivo en la medida en que cada paso que se da significa trazar una línea en el mapa vacío de la historia. Pero también tiene sus peligros: una línea mal trazada puede llevarnos en una dirección errónea o adentrarnos en un laberinto sin salida.

Para las jóvenes generaciones, los mapas convencionales pueden parecerles una interpretación obsoleta y precaria del mundo, comparados con la percepción aparentemente literal de la realidad y con las posibilidades interactivas del Google Maps o del Google Earth. Sin embargo, la forma de

\footnotetext{
${ }^{1}$ Lo normal era que se citasen fotógrafos extranjeros que pasaron por España en distintas épocas. No obstante, Beaumont Newhall no mencionó ni un solo autor español en The History of Photography from 1839 to the Present, que en España se publicó por primera vez, en 1983. Sin embargo, en A Concise History of Photography (1965. Londres: Thames and Hudson), que en España se tradujo como Historia Gráfica de la fotografía (1967. Barcelona: Omega), Helmut y Alison Gernsheim señalaron la actividad en España de fotógrafos como Charles Clifford, August Jacob Lorent, Henri Cartier-Bresson, Robert Capa, Eugene Smith, David Seymour, y George Oddner. No es casualidad que el único nombre español que apareció recogido en este libro fuese el de José Ortiz Echagüe, pues durante muchos años fue una de las pocas referencias internacionales de la fotografía española. A estos nombres, Jean A. Keim en su Histoire de la Photographie (1970. París: Presses Universitaires de France), traducido al castellano al año siguiente por la editorial Oikos-Tau, de Barcelona, incorporó algunas pocas referencias nuevas, entre las que destacaba sobre todo la de Josep Renau.
} 
mirar y conocer el mundo a través de estas nuevas aplicaciones virtuales de localización nos sirven para explicar, aunque sea de un modo metafórico, determinadas estrategias de construcción de la historia de la fotografía.

Creemos saber mucho, incluso tenemos la impresión de que poco más se puede decir sobre nuestro conocimiento de ese territorio que llamamos historia de la fotografía: elegimos un punto que queremos visitar y en nuestro ordenador se van desplegando pantallas de aproximación, conforme activamos la tecla de alejamiento o acercamiento en el menú correspondiente. En las versiones iniciales de estos programas, ese conocimiento integral era una mera ilusión pues llegados a un cierto nivel de proximidad, la realidad se pixelaba, se difuminaba: simplemente no había datos. Estos mapas virtuales miraban entonces el mundo como lo haría un hipermétrope: desde lejos la visión es perfecta pero al acercarse, a veces, las cosas ya no se ven bien, no se distinguen, no se perciben.

Como no podía ser de otra manera, las historias generales de la fotografía han operado del mismo modo, es decir, creando el gran marco, la gran estructura absoluta que atiende a lo esencial y prescinde de los detalles. Pero al igual que esos vacíos de antaño del Google Earth tenían en muchas ocasiones un significado geopolítico, creando zonas reservadas de conocimiento o lugares vedados a la contemplación por motivos estratégicos, o simplemente expresaban zonas de escaso interés, también las historias convencionales de la fotografía han sido creadas a partir de una metodología de intereses muy diversos y no siempre evidentes para el lector, como pueden ser la puesta en valor de determinadas colecciones, la autoridad dogmática de ciertas instituciones, o las reivindicaciones hegemónicas de unas historias nacionales sobre otras ${ }^{2}$.

\footnotetext{
${ }^{2}$ Buena parte de las historias de la fotografía están impregnadas de los intereses -por otro lado, legítimos y comprensibles-, del reconocimiento y puesta en valor de determinadas colecciones fotográficas. Por ejemplo, una gran parte de la historia de Gernsheim está basada en su propia colección, que había sido adquirida por la Universidad de Texas, en Austin. Y muchos trabajos de Newhall, implicaban el reconocimiento y difusión de las colecciones de aquellas instituciones para las que trabajó (Museum of Modern Art, Georges Eastman House). A pesar de defender el carácter internacional de toda investigación sobre
} 
Un mapa virtual de la historia de la fotografía nos mostraría un planeta desequilibrado, con múltiples zonas oscuras - pixeladas, sin datos-, junto a unos potentes focos de la historia, zonas con una alta resolución de imagen, concentradas en unos pocos centros dominantes de Europa y de Estados Unidos. De hecho, las primeras grandes historias generales de la fotografía, en la línea de los citados Newhall o Gernsheim, reproducían un esquema de posiciones jerárquicas irradiadas desde esos centros, o dicho de otro modo, reproducían un modelo centralizado, único y parcial de comprensión de la propia historia de la fotografía ordenado a partir de sus hitos más relevantes y de sus protagonistas más significativos. Todo lo demás era accesorio, suburbial; todo lo demás quedaba o bien subordinado y sometido, o bien desplazado de ese eje medular.

Una historia renovada de la fotografía debería cuestionar ese modelo y reconstruirse a partir de una mirada desde los suburbios históricos: no se trata de negar el papel que esos centros de influencia jugaron en la conformación de la historia, ni siquiera de desmontar los argumentos de los historiadores generales de la fotografía, pues al fin y al cabo, sus historias fueron una respuesta histórica al problema de hacer la historia. Se trataría más bien de hacer visible lo que esa mirada relegó a un segundo plano. Así, la misión actual de la historia de la fotografía quedaría bifurcada en una doble labor: por un lado, revisar desde la crítica las fuentes utilizadas; y, por otro, dar forma a los vacíos de la historia, no desde la perspectiva de una revancha sino desde la voluntad de completar y complementar las visiones, interpretaciones y conocimientos anteriores.

\section{Orígenes de la historia}

La historia de la fotografía en España es una disciplina reciente que nació de esa conciencia de pertenecer al otro lado, de estar en la parte vacía del mapa 
de la historia. Como hemos dicho, ese vacío fue también y ante todo, responsabilidad de los propios historiadores españoles más interesados en otras áreas de la investigación cultural, que dieron siempre la espalda al estudio histórico de la fotografía, vetando su incorporación a los ámbitos académicos universitarios y frenando cualquier posibilidad de recuperación de un legado patrimonial en peligro. Por supuesto, que la fotografía interesaba a los historiadores pero ese interés era puramente instrumental: la fotografía era una imagen que servía para ilustrar la historia no una imagen que tuviera una historia que mereciera de ser contada.

La primera referencia bibliográfica a la historia de la fotografía en España digna de mención -exceptuando un amplio y casi desconocido conjunto de artículos publicados en la prensa española desde la segunda mitad del siglo XIX-, no surgió hasta 1954 con la publicación de la Historia de la fotografía, de Hermenegildo Alsina Munné, encuadernador catalán y fotógrafo aficionado que llegó a ser director del Conservatori de les Arts del Llibre (Escola d'Arts Aplicades), de Barcelona: se trata de un pequeño libro concebido como un manual que no aspiraba "a agotar la materia, pero sí a servir de eficaz introducción a la historia de uno de los descubrimientos más maravillosos y útiles de la humanidad", y que pretendía "dar todo lo fundamental" de la historia de la fotografía, desde sus antecedentes hasta la actualidad, con la intención de mostrar lo que él llamó "la marcha de los estilos, de los gustos y de la moda" (Alsina, 1954, p.11).

Alsina Munné, que defendía una "noción de la fotografía como arte" impregnado de las "corrientes modernas", ya planteaba en la introducción de su libro un hecho significativo: "la bibliografía española sobre fotografía se ciñe casi con exclusividad a la parte técnica”. Tal vez por eso, y consciente del déficit de información sobre la propia historia de la fotografía en España, introdujo una serie de referencias, vinculadas especialmente a los "orígenes" de la fotografía (la posible invención española de la fotografía a partir de unos hipotéticos experimentos en 1837 del pintor aragonés José Ramos Zapetti), con el objeto de ubicar ciertas experiencias españolas en el contexto 
de una historia universal de la imagen fotográfica. Aunque él mismo admitió que las aportaciones españolas a los avances de la fotografía en el siglo XIX eran insignificantes frente a los "descubrimientos ingleses y franceses", el principal valor del libro de Alsina Munné fue llamar la atención, desde un tímido sentimiento nacional, sobre determinados acontecimientos españoles que podrían incorporarse a las historias generales del medio.

Sin embargo, conviene no olvidar dos cosas: por un lado, que esos datos habían sido ya reseñados en algunos textos anteriores, especialmente en el librito Les Origines de la Photographie -que él mismo utilizó como fuente-, publicado en 1914, en el que apareció, junto a otro texto de E.N. Santini (Santini, 1914), el artículo "Sur la decóuverte de la Photographie", escrito por René d'Héliécourt para la Photo-Revue en mayo de 1903 (D’Héliécourt, 1914), donde tachaba esta supuesta invención española de pura anécdota y de ingeniosa leyenda. D'Heliécourt se basaba a su vez, en la información y refutaciones que sobre este tema le había remitido Gabriel Guillon, quien a su vez se hacía eco del artículo que la revista La Fotografía había publicado en marzo de 1903 (Cánovas, 1903), reproduciendo el texto que el crítico de arte Francisco Alcántara, -el primero en difundir estas noticias-, había presentado un año antes en Madrid científico (Alcántara, 1902). Esta complicada trama de citas y de alusiones dejaba en evidencia la endeblez inicial de la historia de la fotografía española no solo por la reprimenda metodológica por parte de los historiadores franceses de la que, con toda razón, habían sido objeto Alcántara y La Fotografía, sino porque Alsina Munné buscó y certificó en la historiografía francesa lo que la propia bibliografía española había aportado ya.

Por otro lado, hay que tener en cuenta que ese deseo de reivindicar "lo español" en un contexto histórico general respondía a un proceso de mimetización de metodologías y de asimilación de las tesis de un modelo normativo según el cual la historia de la fotografía no sería otra cosa que la historia de unos centros emisores dinámicos (de donde partiría "lo original y 
lo nuevo") conectados a una red de estaciones receptoras pasivas (cuyas aportaciones serían mínimas e inapreciables).

\section{Las primeras historias}

Tuvieron que pasar más de dos décadas para que, con la salvedad de alguna aportación esporádica y parcial (Campañá, 1969), se produjera la auténtica eclosión de los estudios sobre historia de la fotografía en España: a mediados de los años 70, coincidiendo con los momentos finales de la dictadura de Franco, se inició un proceso clave de inflexión en esa tendencia de abandono y orfandad de la fotografía. Fue una época de continua experimentación, de esperanzas colectivas y de renovación general: cada pequeña intervención tuviera éxito o no, significaba un gran paso que ayudaba a consolidar experiencias, apoyos institucionales, apuestas empresariales y, sobre todo, una nueva sensibilidad del público hacia la fotografía. Cada gesto -llámese libro, exposición, catálogo, jornadas, o encuentros- suponía completar las lagunas interminables de una historia por hacer. Podríamos decir que el escenario natural de la fotografía en este periodo no era otro que el vacío: tal vez por eso, la primera frase de la Historia de la fotografía que Marie-Loup Sougez publicó en Madrid en 1981 hacía alusión al "hueco" que su libro venía a llenar en la bibliografía nacional (Sougez, 1981, p. 9).

El comienzo de la década de los 80 supuso el primer eslabón de una serie de hitos fundamentales para completar esos innumerables huecos de la historia de la fotografía en España con la aparición en 1981, en un margen muy corto de tiempo, de los libros de Lee Fontanella, La historia de la fotografía en España desde sus orígenes hasta 1900 (Fontanella, 1981), el ya mencionado de Sougez (con varios capítulos y epígrafes dedicados a España), o los primeros trabajos de divulgación de Miguel Ángel Yañez Polo -sobre fotografía sevillana (Yañez Polo, 1981)-, o de Publio López Mondéjar -sobre fotografía manchega (López Mondejar, 1981; 1984)-, que derivarían, a partir 
de 1989, en su trilogía sobre Las fuentes de la memoria ${ }^{3}$. A estos primeros libros sobre la historia de la fotografía en España, habría que añadir también los apéndices de Josep María Casademont y de Joan Fontcuberta incluidos respectivamente, en sendas traducciones al castellano de los libros de Petr Tausk, La fotografía del siglo XX. De la fotografía artística al periodismo gráfico (Casademont, 1978), y de Beaumont Newhall, Historia de la Fotografía. Desde sus orígenes hasta nuestros días (Fontcuberta, 1983), ambos editados por Gustavo Gili.

El propósito de estos dos apéndices era ofrecer una aproximación a la propia historia de la fotografía en España teniendo en cuenta los conocimientos, en algunos casos muy parciales, que de ella se tenía por entonces. Pero también tenían la función de aportar los datos sobre España que no aparecían en los textos de Tausk y de Newhall. Así, esos apéndices corregían en parte las omisiones a la fotografía española pero no resolvían el problema de la inserción del caso español en un contexto global. El modelo era muy simple: existía una historia general de la fotografía en la que la fotografía española sólo podía aspirar a ser un apéndice descontextualizado.

En cualquier caso, las citadas hasta aquí iban a ser las referencias bibliográficas disponibles para una nueva generación de historiadores de la fotografía, muchos de los cuales contaban con una formación académica en campos como la Historia o la Historia del Arte, o procedían de otros ámbitos como los archivos o las bibliotecas, una formación y unas actividades que hasta entonces habían obviado y prescindido de cualquier análisis histórico de la fotografía. De este modo, los nuevos investigadores de la fotografía, autodidactas por necesidad, aplicaron lo que podríamos llamar un modelo sin modelo, un modelo de urgencia donde casi todo era posible, donde cualquier enfoque a la dimensión histórica del fenómeno era válido, desde las valoraciones más superficiales a las indagaciones más rigurosas, tal y como se puso de manifiesto en el I Congreso de Historia de la fotografía española,

\footnotetext{
${ }^{3}$ Los tres volúmenes, publicados por Lunwerg, en 1989, 1992 y 1996, llevan por título: Fotografía y sociedad en la España del siglo XIX; Fotografía y sociedad en España, 19oo1939; y, Fotografía y sociedad en la España de Franco, 1939-1975.
} 
celebrado en Sevilla en 1986 (AA.VV., 1986), que funcionó como plataforma de presentación y consolidación de las numerosas historias locales que se venían haciendo en España en los últimos años.

\section{Las historias locales}

Los dos aspectos que caracterizaron el rumbo de las historias locales de la fotografía en España fueron su acotación temporal -puesto que casi todas acababan en 1936 o 1939, es decir en el comienzo o en el final de la Guerra civil-, y su limitación territorial, en unas tipologías variables que iban desde un ámbito más amplio - regional o provincial- a uno más cercano -comarcal o municipal. La enorme repercusión de este fenómeno no puede obviarse y merece un análisis más detallado ya que en la explicación de ese interés repentino por los estudios locales de la fotografía encontraremos algunas claves para explicar los derroteros metodológicos principales de nuestra historia de la fotografía.

Aunque podríamos plantear argumentos más abstractos, como la falta de una tradición de estudios de dimensión supranacional o la existencia de un cierto pudor de nuestros investigadores para profundizar desde España en temas o autores internacionales, lo cierto es que la nueva reestructuración política del país con la llegada de la democracia, recogida en la Constitución española de 1978 y desarrollada a partir de la aprobación de los distintos Estatutos de Autonomía entre los años 1979 y 1983, propició un clima favorable de reivindicación regional que demandaba una recuperación de la memoria histórica e incluso, la reconstrucción -cuando no la invención- de una identidad común regional que veía en las fotografías "antiguas" un salvoconducto gráfico al pasado para explicar las particularidades diferenciadoras de las nuevas 17 comunidades y 2 ciudades autónomas en las que se dividió el país.

Pero al margen de esa explicación política que alentó este tipo de trabajos, existen otras razones de peso que tienen que ver con la ausencia de una 
tradición historiográfica y la falta de experiencias metodológicas sobre la materia. A ese analfabetismo de la investigación histórica fotográfica hubo que sumar el desconocimiento de la propia historia ya que la mayor parte de las informaciones, datos y materiales de los que se disponían conformaban un legado incompleto y muy fragmentado. Para los nuevos investigadores de la fotografía -muchos de ellos jóvenes universitarios que iniciaban estos trabajos en el formato de una tesis doctoral-, era más fácil afrontar una investigación local pues la cercanía a la documentación y a los archivos y colecciones, en su mayoría mal organizados o en pésimo estado, garantizaba un cierto éxito y facilitaba una labor realizada a partir de métodos puramente intuitivos y no contrastados.

De este modo, en las últimas décadas del siglo XX la bibliografía sobre historias locales de la fotografía en España se incrementó de una manera asombrosa: Valladolid (González, 1990), Cádiz (Garófano Sánchez, 1993), Málaga (Fernández Rivero, 1994), Canarias (Vega, 1995; 1997; Teixidor Cadenas, 1999), Sevilla (Yañez Polo, 1997), Granada (Piñar Samos, 1997), Gijón (Cabriffosse Cuesta, 2000), o Mallorca (Mulet, 2001), fueron algunos de los puntos geográficos asociados a este fenómeno. Además, no hay que olvidar la trayectoria que siguieron algunos investigadores ya que los mismos que trabajaron en un primer momento sobre un nivel más próximo (comarcal o provincial) terminarían presentando, a partir del año 2000, los resultados de investigaciones más globales como los publicados sobre Cataluña (AA.VV., 2000), Castilla y León (González, 2002), Canarias (Vega, 2002), o Murcia (Díaz Burgos, y Tejada Martín, 2001; 2003), que se sumaban a algunos trabajos anteriores sobre Cantabria (Riego, y Hoz, 1987), Navarra (Cánovas, 1989), Valencia (AA.VV., 1990; AA.VV., 1992), o La Rioja (Rocandio, 1992), entre otros. Si bien estas historias regionales no cerraban todas las posibilidades de estudio, sí consolidaban un conocimiento más exacto de la materia y, sobre todo, unas nuevas pautas metodológicas de análisis de la historia de la fotografía en cada una de esas regiones. 
Convendría no minimizar el esfuerzo que algunos de estos nuevos historiadores hicieron para denunciar la debilidad y el agotamiento de los modelos inicialmente utilizados para hacer sus historias. $Y$ esta fue una tarea que tuvieron que asumir al mismo tiempo que avanzaban en sus investigaciones. En este sentido, la historiografía española dispone de algunas obras destinadas específicamente a las cuestiones metodológicas sobre la historia de la fotografía. Uno de los libros pioneros en esta línea fue Fotografía y métodos históricos: dos textos para un debate, publicado de forma conjunta por las Aulas de Fotografía de las Universidades de Cantabria y de La Laguna, con sendos ensayos de Bernardo Riego y Carmelo Vega, titulados respectivamente "De la fotohistoria a la historia con la fotografía. La historiografía española y los debates internacionales sobre la Fotografía como objeto histórico", e "Imágenes contaminadas. La fotografía en la Historia del Arte" (Riego, y Vega, 1994). Igualmente deben citarse algunos textos publicados en las actas del I Congreso Universitario sobre Fotografía Española, celebrado en Pamplona en 1999 bajo el título de Historia de la fotografía del siglo XIX en España: una revisión metodológica (AA.VV., 2002), en el que participaron investigadores españoles y extranjeros. Ese mismo año apareció también el libro Fotografía. Crisis de historia, en edición coordinada por Joan Fontcuberta y con textos de historiadores y ensayistas españoles y extranjeros interesados en la reflexión sobre los modelos y métodos de la historia de la fotografía (Fontcuberta, 2002).

\section{Una distancia adecuada}

Hemos dicho ya que el modelo de visión de las historias generales de la fotografía ha sido el del hipermétrope, el que mira las cosas desde lejos. Por contra, los historiadores locales de la fotografía en España pensaron y miraron en los años 80, como lo haría un miope. Asegura el diccionario que la miopía es un "defecto" de la visión que impide enfocar los objetos situados a cierta distancia, es decir lo que está lejos. Afirma el diccionario también que la miopía significa, en sentido negativo, "cortedad de alcances o de miras". Es 
indudable que esa "cortedad" existió en muchos de los trabajos que se hicieron en aquella época, pero no creo que debamos entenderla como un defecto sino más bien como un síntoma de las circunstancias del momento: necesitábamos datos, necesitábamos rellenar huecos, necesitábamos poner nombre a las personas y a las cosas que ni siquiera sabíamos que existían, necesitábamos imágenes para hablar de las imágenes, necesitábamos ser arqueólogos de la fotografía al mismo tiempo que nos formábamos como historiadores de la fotografía, necesitábamos buscar, rebuscar, indagar, revolver, encontrar y descubrir esos tesoros cercanos de la fotografía que durante tanto tiempo habían permanecido enterrados.

En mi opinión, no estamos tanto ante un problema de distancia como ante una cuestión de escala. Al fin y al cabo, la hipermetropía es también un defecto que nos hace ver de una manera confusa las cosas cercanas. El asunto no es elegir entre la disyuntiva cercano-lejano sino establecer los parámetros adecuados para comprender los fenómenos históricos de la fotografía. Digo "comprender" y no "comprender correctamente" porque eso significaría de nuevo, aceptar que hay un modelo único de historia, una sola forma de visión de las cosas. Las gafas invisibles que nos ponemos para corregir los defectos de la visión que hemos ido adquiriendo a lo largo del tiempo no pueden convertirnos en ciegos. Esas gafas nos deben ayudar a mantener una forzosa "distancia" crítica con nuestras maneras de entender la historia de la fotografía, de modo que nos permita ver las cosas de cerca viéndolas de lejos, y ver las cosas de lejos sin descuidar verlas de cerca.

Volvamos a nuestro metafórico Google Earth de la historia de la fotografía. Como en todo mapa, encontramos una escala, una medida estándar que nos permite la representación proporcionada de las cosas y que nos ofrece el tamaño exacto de cada punto geográfico y la relación de equidistancia con los demás puntos de un espacio determinado, además de la conexión entre los distintos espacios que conforman un todo uniforme. Sólo si somos conscientes de la escala que utilizamos para leer el mapa podremos percibir la dimensión exacta de aquello que vemos y podremos estudiar en un mismo 
plano las realidades semejantes pero también las distintas. Eso exactamente es lo que ocurre, por ejemplo, cuando consultamos una carta de colores: esa escala nos muestra una estructura ordenada donde se interrelacionan "valores distintos de una misma cualidad". Tal vez en nuestro papel como historiadores deberíamos aprender del diseño de unas hipotéticas cartas de colores de la fotografía: así aprenderíamos que cada color tiene su importancia en sí mismo y en relación con los demás; que existen muchos colores y que cada color puede tener matices infinitos. En una carta de colores, cada uno de ellos tiene su código, su peculiaridad y sus diferencias, aunque parezcan similares. Todos son distintos y todos son importantes: todo depende del color que busquemos, del matiz que necesitamos.

Cuando la historia de la fotografía en España sea un territorio sin vacíos, deberemos ajustar las escalas para trazar su mapa. Aprendamos de las nuevas cartografías del siglo XXI para no seguir perdiéndonos. Lo interesante del Google Earth es su capacidad para superponer tramas, para ubicar en un mismo plano representaciones distintas de una misma realidad: así, el mapa convencional puede mostrar también el callejero, y ambos se pueden superponer sobre una imagen del lugar tomada desde un satélite, y a todo ello se puede añadir una batería de información enlazada de fotografías, vídeos, wikipedia, cámaras web, e incluso, recorridos virtuales en tres dimensiones por las calles de casi cualquier lugar del mundo. Por supuesto, existe siempre el peligro de que un exceso de información acabe finalmente ocultando el mapa de la historia que nos guiaba, pero ese riesgo debemos asumirlo como parte de nuestras prácticas cotidianas para diseccionar la historia.

¿Podemos imaginar un mapa que sólo recoja las autopistas que unen las capitales con las grandes ciudades de un país? Una historia general de la fotografía en España no puede seguir sustentándose sobre sus vacíos para consolidarse sobre los grandes nombres conocidos o sobre los nombres que interesa conocer por los motivos que sean. También es verdad que no puede hacerlo recorriendo sólo los caminos vecinales y las carreteras comarcales. 
Tiene que haber, por tanto, un punto intermedio en esa confluencia de tramas superpuestas que permita conectar experiencias, destacando los grandes nombres que han marcado el camino a seguir en cada momento pero también otros nombres y experiencias periféricas relegadas a un segundo plano, no porque sean peores sino simplemente porque hasta ahora se desconocían. La escala sigue siendo aquí necesaria pues corremos el riesgo, como así ha ocurrido en nuestro país, de proyectar de manera desequilibrada la producción de determinados fotógrafos en detrimento de otros.

\section{Conclusiones: repensar la historia}

El papel del historiador de la fotografía en España pasaría hoy por la definición de algunas de esas tramas que permitan vincular los resultados de treinta años de investigaciones de carácter local a un contexto nacional. ¿Qué sentido tendría en estos momentos seguir manteniendo una historia de la fotografía en España que prescinda, por modestos que sean, de los hallazgos rescatados a partir de esas múltiples historias locales? Igualmente, ¿qué sentido tendría hoy continuar unas historias locales desvinculadas y descontextualizadas de un devenir colectivo nacional o internacional? Desde ese punto intermedio, cualquier intento de repensar hoy la historia de la fotografía en España requiere de acciones puntuales pero absolutamente ineludibles que implicarían:

1. la autocrítica de las metodologías empleadas y la búsqueda de modelos renovados de aproximación a la fotografía como hecho histórico;

2. la revisión crítica de las fuentes que nos permita saber cómo se ha construido y sobre qué bases documentales se han enunciado las historias de la fotografía en España; y,

3. la actualización de los estudios sobre el patrimonio fotográfico, mediante la realización y publicación de guías, catálogos e inventarios que nos permitan conocer la dimensión exacta del legado fotográfico español, tal y como se ha hecho, entre otros lugares, en Cataluña (Zelich, 1996), Baleares 
(Aguiló, y Mulet, 2004), o, más recientemente en Canarias (Vega, 2014).

Necesitamos los viejos mapas para saber de dónde venimos pero también para asegurarnos del destino al que vamos: de los pasos errados, de los senderos perdidos, también se aprende cuando lo que se quiere es buscar un camino. Necesitamos mapas precisos para afrontar los derroteros de una renovada historia de la fotografía en España. Pero, sobre todo, necesitamos ajustar la escala, adecuar la dimensión, reivindicarnos frente al vacío.

\section{Referencias bibliográficas}

AA.VV. (1986). Historia de la fotografía española, 1839-1986, Actas del I Congreso de Historia de la fotografía española. Sevilla: Sociedad de Historia de la fotografía española.

AA.VV. (1990). Historia de la fotografía valenciana. Valencia: Levante- El Mercantil Valenciano.

AA.VV. (1992). Memoria de la luz: fotografía en la Comunidad valenciana, 1839-1939. Barcelona: Lunwerg Editores.

AA.VV. (2000). Introducción a la Historia de la Fotografía en Cataluña. Barcelona: Lunwerg Editores y Museo Nacional d'Art de Catalunya.

AA.VV. (2002). Historia de la fotografía del siglo XIX en España: una revisión metodológica. Actas del I Congreso Universitario sobre Fotografía Española. Pamplona: Gobierno de Navarra.

Aguiló, C., y Mulet, M.-J. (2004). Guia d'arxius, col-leccions y fons fotogràfics $i$ cinematogràfics de les Balears, 1840-1967. Baleares: Universitat de les Illes Balears y "SA NOSTRA" Caixa de Balears.

Alcántara, F. (1902). ¿El inventor de la fotografía? Madrid científico, (398), 312-313. Madrid.

Alsina Munné, H. (1954). Historia de la fotografía. Barcelona: Producciones Editoriales del Nordeste.

Cabriffosse Cuesta, F. (2000). Historia de la fotografía en Gijón (18391936). Gijón: Fundación Municipal de Cultura, Educación y Universidad Popular.

Campañá Bandranas, A. (1969). La fotografía en Barcelona. Miscellanea Barcinonensia. Revista de investigación y alta cultura, VIII, (XXI), 13-20. Barcelona: Ayuntamiento de Barcelona.

Cánovas, A. (1903). Crónica. La Fotografía (18), 161-165. Madrid. 
Cánovas, C. (1989). Apuntes para una historia de la fotografía en Navarra. Pamplona: Departamento de Educación y Cultura, Gobierno de Navarra.

Casademont, J. M. (1978). La fotografía en el Estado español (1900-1978). En P. Tausk, La fotografía del siglo XX. De la fotografía artística al periodismo gráfico (pp. 261-270). Barcelona: Gustavo Gili.

D'Héliécourt, R. (1914). Sur la decóuverte de la Photographie. En Les Origines de la Photographie (pp. 23-32). París: Bibliothèque de la Photo-Revue, Charles Mendel.

Díaz Burgos, J. M., y Tejada Martín, I. (2001). La Imagen Rescatada, 18631940, fotografía en la Región de Murcia. Murcia: Murcia Cultural.

Díaz Burgos, J. M., y Tejada Martín, I. (2003). Fotografía en la Región de Murcia, 1940-2003, Murcia, Murcia Cultural.

Fernández Rivero, J.A. (1994). Historia de la fotografía en Málaga durante el siglo XIX. Málaga: Miramar.

Fontcuberta, J. (1983). Notas sobre la fotografía española. En B. Newhall, Historia de la Fotografía. Desde sus orígenes hasta nuestros días (pp. 300-322). Barcelona: Gustavo Gili.

Fontcuberta, J. (Ed.) (2002). Fotografía. Crisis de historia. Barcelona: Actar.

Fontanella, L. (1981). La historia de la fotografía en España desde sus orígenes hasta 190o. Madrid: Ediciones El Viso.

Garófano Sánchez, R. (1993). Cádiz en la fotografía del siglo XIX. Cádiz: Unicaja.

Gernsheim, H., y A. (1967). Historia Gráfica de la fotografía. Barcelona: Omega.

González, R. (1990). Luces de un siglo. Fotografía en Valladolid en el siglo $X I X$. Valladolid: Gonzalo Blanco.

González, R. (2002). El asombro en la mirada. 100 años de fotografía en Castilla y León (1839-1939). Salamanca: Consorcio Salamanca 2002.

López Mondejar, P. (1981). Retratos de la vida (1875-1939). Madrid: Blume.

López Mondejar, P. (1984). Crónica de la luz: fotografía en Castilla-La Mancha (1855-1936). Madrid: El Viso.

Keim, J.A. (1971). Historia de la fotografía. Barcelona: Oikos-Tau.

Mulet, M.-J. (2001). Fotografía a Mallorca, 1839-1936. Barcelona: Lunwerg Editores.

Newhall, B. (1983). Historia de la Fotografía. Desde sus orígenes hasta nuestros días. Barcelona: Gustavo Gili. 
Piñar Samos, J. (1997). Fotografía y fotógrafos en la Granada del siglo XIX. Granada: Caja General de Ahorros de Granada y Ayuntamiento de Granada.

Riego, B., y Hoz, Á. de la (1987). Cien años de fotografía en Cantabria. Barcelona: Lunwerg Editores.

Riego, B., y Vega, C. (1994). Fotografía y métodos históricos: dos textos para un debate. Santander: Aula de Fotografía Universidad de Cantabria y Aula de Fotografía Universidad de La Laguna.

Rocandio, J. (1992). Cien años de fotografía en la Rioja. Logroño: Cultural Rioja.

Santini, E.N. (1914). La decóuverte de la photographie. En Les Origines de la Photographie (pp. 5-22). París: Bibliothèque de la Photo-Revue, Charles Mendel.

Sougez, M.-L. (1981). Historia de la fotografía. Madrid: Ediciones Cátedra.

Tausk, P. (1978). La fotografía del siglo XX. De la fotografía artística al periodismo gráfico. Barcelona: Gustavo Gili.

Teixidor Cadenas, C. (1999). La fotografía en Canarias y Madeira. La época del daguerrotipo, el colodión y la albúmina, 1839-19oo. Madrid: Carlos Teixidor Cadenas.

Vega, C. (1995; 1997). La isla mirada. Tenerife y la fotografía (1839-1939), 2 vols. Santa Cruz de Tenerife: Centro de Fotografía Isla de Tenerife.

Vega, C. (2002). Derroteros de la fotografía en Canarias (1839-200o). Santa Cruz de Tenerife: CajaCanarias y La Caja de Canarias.

Vega, C. (Dir.), (2014). Guía-inventario de fondos y colecciones de fotografía en Canarias. Tenerife: Fundación General Universidad de La Laguna, y Gobierno de Canarias.

Yáñez Polo, M. Á. (1981). Retratistas y fotógrafos. Sevilla: Grupo Andaluz de Ediciones.

Yáñez Polo, M. Á. (1997). Historia general de la fotografía en Sevilla. Sevilla: Sociedad Nicolás Monardes y Sociedad de Historia de la Fotografía Española.

Zelich, C. (ed.), (1996). Llibre blanc del patrimoni fotogràfic a Catalunya. Barcelona: Generalitat de Catalunya, Departament de Cultura.

Cómo citar: Vega, C. (2015). "Un modelo sin modelo. Repensar la historia de la fotografía en España". Fotocinema. Revista científica de cine y fotografía, $\quad 10, \quad \mathrm{pp} . \quad 57-74 . \quad$ Disponible: http://www.revistafotocinema.com/index.php?journal=fotocinema\&page=article\&op =view\&path[]=277 